\title{
Percepção dos idosos em tratamento de hemodiálise
}

\author{
Perception of the elderly undergoing hemodialysis treatment \\ Percepcíon del anciano em tratamento de hemodiálisis
}

Recebido: 17/03/2021 | Revisado: 26/03/2021 | Aceito: 29/03/2021 | Publicado: 09/04/2021

\author{
Ana Claudia Barbosa Florencio \\ ORCID: https://orcid.org/0000-0002-1850-2610 \\ Universidade do Estado de Mato Grosso, Brasil \\ E-mail: ana.claudia.florencio@gmail.com \\ Bianca Teshima de Alencar \\ ORCID: https://orcid.org/0000-0001-6812-3494 \\ Universidade do Estado de Mato Grosso, Brasil \\ E-mail: bianca.teshima@unemat.br \\ Helena Gonçalves Marins \\ ORCID: https://orcid.org/0000-0002-5598-6220 \\ Centro de Tratamento do Rim, Brasil \\ E-mail: helena.marins.ctr@gmail.com \\ Rafael Teshima de Alencar \\ ORCID: https://orcid.org/0000-0001-7103-9998 \\ Universidade do Estado de Mato Grosso, Brasil \\ E-mail:teshima12@hotmail.com \\ Samira Michel Garcia Campos \\ ORCID: https://orcid.org/0000-0003-2040-8516 \\ Universidade do Estado de Mato Grosso, Brasil \\ E-mail:samira@unemat.br \\ Shaiana Vilella Hartwig \\ ORCID: https://orcid.org/0000-0003-4245-2163 \\ Universidade do Estado de Mato Grosso, Brasil \\ E-mail:shaiana.hartwig@unemat.br
}

\begin{abstract}
Resumo
Conforme a população envelhece, aumenta o número de doenças crônicas não transmissíveis, dentre elas a insuficiência renal crônica, que em fase terminal leva o paciente a realizar uma terapia renal substitutiva, um dos métodos é na forma de hemodiálise, um tratamento que mantêm a vida, porém exige do paciente conviver com as restrições impostas pelas condições de saúde e tratamento. O objetivo deste trabalho é reconhecer as principais dificuldades vivenciadas pelos idosos em tratamento de hemodiálise no município de Cáceres-MT. Trata-se de um estudo descritivo, exploratório, de abordagem qualitativa, realizado com 16 idosos, entre os meses de agosto à novembro de 2020 para a entrevista utilizou-se um questionário semiestruturado contendo perguntas abertas. Entre os idosos entrevistados, 50\% eram do sexo masculino e 50\% feminino, com uma idade que variou de 60 a 81 anos. Após a análise das entrevistas obtivemos três categorias: percepções e vivências acerca do impacto da doença e o processo de aceitação do tratamento de hemodiálise; o idoso em tratamento de hemodiálise: principais dificuldades vivenciadas; e fé, família e equipe multiprofissional: enfrentamento da doença e apoio na adesão ao tratamento. Este estudo revelou que o idoso em hemodiálise convive com várias limitações e dificuldades, necessitando do total apoio dos familiares, sociedade, principalmente a equipe de enfermagem, ajudando-lhes na resolução das dificuldades encontradas, saber ouvi-los e compreendê-los em sua individualidade e magnitude, criando ações educativas para promover uma melhor qualidade de vida para que apesar das limitações estes idosos possam viver melhor.
\end{abstract}

Palavras-chave: Insuficiência renal crônica; Saúde do idoso; Diálise renal.

\begin{abstract}
As the population ages, the number of non-communicable chronic diseases increases, including chronic renal failure, which in the terminal phase leads the patient to undergo renal replacement therapy, one of the methods is in the form of hemodialysis, a treatment that keeps life, however, it requires the patient to live with the restrictions imposed by health and treatment conditions. The objective of this work is to recognize the main difficulties experienced by the elderly undergoing hemodialysis treatment in the municipality of Cáceres-MT. This is a descriptive, exploratory study with a qualitative approach, carried out with 16 elderly people, between the months of August and November 2020. For the interview, a semi-structured questionnaire containing open questions was used. Among the elderly interviewed, 50\% were male and 50\% female, with an age ranging from 60 to 81 years. After analyzing the interviews, we obtained three categories: perceptions and experiences about the impact of the disease and the process of acceptance of hemodialysis treatment; the elderly undergoing hemodialysis treatment: main difficulties
\end{abstract}


experienced; and faith, family and multiprofessional team: coping with the disease and supporting adherence to treatment. This study revealed that the elderly on hemodialysis live with several limitations and difficulties, needing the full support of family members, society, especially the nursing team, helping them to solve the difficulties encountered, knowing how to listen to them and understanding them in their individuality and magnitude, creating educational actions to promote a better quality of life so that despite the limitations these elderly people can live better.

Keywords: Chronic kidney failure; Health of the elderly; Renal dialysis.

\begin{abstract}
Resumen
A medida que la población envejece aumenta el número de enfermedades crónicas no transmisibles, incluida la insuficiencia renal crónica, que en la fase terminal lleva al paciente a someterse a una terapia de reemplazo renal, uno de los métodos es la hemodiálisis, un tratamiento que mantiene la vida. sin embargo, requiere que el paciente viva con las restricciones impuestas por las condiciones de salud y tratamiento. El objetivo de este trabajo es reconocer las principales dificultades que experimentan los ancianos sometidos a tratamiento de hemodiálisis en el municipio de Cáceres-MT. Se trata de un estudio descriptivo, exploratorio, con abordaje cualitativo, realizado con 16 personas mayores, entre los meses de agosto y noviembre de 2020. Para la entrevista se utilizó un cuestionario semiestructurado con preguntas abiertas. Entre los ancianos entrevistados, el 50\% eran hombres y el 50\% mujeres, con un rango de edad de 60 a 81 años. Tras analizar las entrevistas, obtuvimos tres categorías: percepciones y experiencias sobre el impacto de la enfermedad y el proceso de aceptación del tratamiento de hemodiálisis; ancianos en tratamiento de hemodiálisis: principales dificultades experimentadas; y fe, familia y equipo multiprofesional: afrontamiento de la enfermedad y apoyo a la adherencia al tratamiento. Este estudio reveló que los ancianos en hemodiálisis viven con varias limitaciones y dificultades, necesitando el apoyo total de los familiares, de la sociedad, especialmente del equipo de enfermería, ayudándolos a resolver las dificultades encontradas, sabiendo escucharlos y comprenderlos en su individualidad y magnitud, creando acciones educativas para promover una mejor calidad de vida para que a pesar de las limitaciones estas personas mayores puedan vivir mejor.
\end{abstract}

Palabras clave: Insuficiencia renal crónica; Salud del anciano; Diálisis renal.

\title{
1. Introdução
}

O processo de envelhecimento da população no Brasil vem ocorrendo devido a mudanças em alguns indicadores de saúde, onde diminui-se a taxa de natalidade e mortalidade e aumentou a expectativa de vida. No Brasil, no ano de 2017, a população de idosos chegou há 30,2 milhões de pessoas (14,6\%), 4,8 milhões a mais que em 2012. No ano de 2017, o Estado de Mato Grosso tinha uma população de 380 mil pessoas idosas. Para 2025, a expectativa, é que no Brasil, tenha cerca de 32 milhões de pessoas com idade igual ou maior há 60 anos. (Brasil, 2006; Pilger et al., 2010; IBGE, 2018).

Conforme aumenta a expectativa de vida, eleva-se também o número de Doenças Crônicas Não Transmissíveis (DCNT), que nos idosos compromete ainda mais sua funcionalidade, pois os processos de envelhecimento levam a alterações orgânicas e funcionais, aumentando o risco de comorbidades. (Brasil, 2006; Pilger et al., 2010).

Dentre as DCNT, a Insuficiência Renal Crônica (IRC), tem ganhado destaque pelo grau de limitações que acarreta na vida dos indivíduos, afetando diretamente seu bem-estar físico e biopsiquicosocial e no âmbito familiar, principalmente em idosos, que já vivenciam nesta fase de vida as alterações fisiológicas do envelhecimento. (Orlandi et al., 2011; Santos, Rocha \& Berardinelli, 2011).

Considerada um problema de saúde pública a nível mundial, a IRC decorre da deterioração lenta, progressiva e irreversível da função renal, advinda da destruição do número de néfrons funcionais. Conforme estes são destruídos a função dos rins torna-se prejudicada, levando a longo prazo, incapacidade de realizar a filtração renal, impossibilitando excreção de metabólitos e de manter o equilíbrio hidroeletrolítico, comprometendo a homeostasia corporal. (Stevens \& Lowe, 2002).

Geralmente nos estágios iniciais a IRC não apresenta sintomas clínicos, porém com a perda gradativa da função renal em pelo menos $70 \%$ a 75\%, abaixo do normal, vai tornando-se sintomática devido a ocorrência do acúmulo de substâncias tóxicas no sangue, sais minerais e líquidos. (Guyton \& Hall, 2011; Oliveira, et al., 2012).

Conforme aumenta a lesão renal e/ou há uma redução acentuada da taxa de filtração glomerular (TFG), o paciente chega na última fase da doença renal crônica (DRC), onde há falência renal, a Doença Renal Crônica Terminal (DRCT), ou 
IRC, também classificado como estágio 5 (cinco) da DRC. Nessa fase indica-se a necessidade de realizar uma terapia renal substitutiva (TRS), na forma de diálise ou transplante renal, para garantir a sobrevivência. A iálise pode ser realizada por meio de hemodiálise (HD) ou diálise peritoneal (DP). (SBN, 2020).

A HD é uma das formas de TRS, utilizada em mais de $92 \%$ dos casos, conforme o censo brasileiro de diálise realizado em 2016 e 2018. (Sesso et al., 2017; Neves et al, 2018) Ela consiste em um procedimento de filtração do sangue através de uma máquina e um dialisador, está por sua vez limpa e filtra o sangue, eliminando do corpo resíduos prejudiciais à saúde, como solutos e líquidos, controlando a pressão arterial (PA), equilibrando substâncias como sódio, potássio, ureia e creatinina, ou seja, um mecanismo que exercem a função dos rins que se apresentam doentes, garantindo assim a manutenção da vida. (Sesso et al., 2017; SBN, 2020).

No censo brasileiro de diálise, do ano de 2018, apresentou um número estimado de 133.464 pacientes com DRCT ou IRC. No mesmo ano, a estimativa de 42.546 pacientes iniciou o tratamento de TRS e com incidência estimada de 204 população por milhão (pmp). A região Centro Oeste teve uma prevalência estimada de 648 pmp, de pacientes em diálise. (Neves et al., 2020).

De acordo com Sesso et al. (2017), em julho de 2016, o Mato Grosso contou com 1.776 pacientes em tratamento dialítico crônico, com uma taxa de prevalência de 537 pmp. Conforme Neves et al. (2020), no ano de 2018, Mato Grosso registrou a incidência de 299 pmp e uma prevalência de 555 pmp de paciente em diálise.

O percentual de pacientes que que iniciaram TRS no Brasil, no ano de 2016 foi de $0,3 \%$ ( $\leq 12$ anos), 0,9\% (entre 13 a 19 anos), $65,7 \%$ (de 20 a 64 anos), $21,8 \%$ (de 65 a 74 anos) e 11,2\% ( $\geq 75$ anos), sendo que a faixa etária de 64 anos acima atingiu $33 \%$ dos novos casos. (Sesso et al., 2017)

O tratamento de HD mantém a vida, entretanto, não substitui todas as funções do rim normal, exigindo do paciente aceitação do diagnóstico e adesão ao tratamento hemodialítico, assim como adaptação a um novo estilo de vida, isto pode trazer ao idoso grandes limitações, frustações, insegurança, medos, devido a alterações decorrentes dos hábitos de vida, até mesmo limitações nas atividades de vida diária, consequentemente a diminuição na qualidade de vida. (Orlandi et al., 2011; Rosa \& Loures, 2013).

A doença e o tratamento causam impactos diferenciados na vida de um paciente para outro, dependendo de como ele vivencia o processo de aceitação da doença e do tratamento de HD, contudo os idosos em tratamento de hemodiálise, tornamse fragilizados, pois além do envelhecimento, há as mudanças acarretadas pela IRC. (Cargnin, et al., 2018).

Vale ressaltar que o paciente vivencia e enfrenta as alterações impostas pelas condições de saúde e pressupõe que estes convivem com várias dificuldades no tratamento hemodiálise como: alterações nos hábitos alimentares e hídricos, mudanças na imagem corporal, interação social, transporte para hemodiálise, condições de trabalho, frequência e tempo destinado as sessões de HD, sintomas pré e pós diálise, enfim bem-estar geral, pois o paciente tem várias áreas da vida afetada, levando a dificuldade de adesão ao tratamento. (Cargnin, et al., 2018).

Contudo, o tratamento torna-se doloroso, visto que os remete a uma condição de dependência a uma máquina, uma rotina terapêutica rigorosa, isto causa desajuste tanto físico-patológico, quanto emocional e diante das dificuldades percebidas, faz despertar o interesse pelo tema, buscando observar as particularidades de cada idoso, na busca de um melhor entendimento de suas principais dificuldades, levantou-se o seguinte problema de pesquisa: Quais são as principais dificuldades vivenciadas pelos idosos em tratamentos de hemodiálise? (Pilger et al., 2010).

A fim de contribuir para o aprofundamento do conhecimento sobre esta temática justifica-se este estudo pela relevância para sociedade, família e profissionais da saúde, principalmente a equipe de enfermagem, pois, diante as dificuldades relatadas, estas poderão servir de alicerce para elaborar propostas de cuidados/orientações aos idosos, que 
facilitem a adesão ao tratamento e as alterações nos hábitos de vida, para que o idoso tenha um melhor enfrentamento da doença e tratamento.

Desta forma, realizou-se o presente estudo objetivando reconhecer as principais dificuldades vivenciadas pelos idosos em tratamento de hemodiálise no Centro de Tratamento do Rim (CTR), do município de Cáceres-MT.

\section{Metodologia}

Estudo descritivo, exploratório, de abordagem qualitativa, realizado no Centro de Tratamento do Rim (CTR) do município de Cáceres-MT. Na pesquisa qualitativa é importante a interpretação dos pesquisadores sobre o fenômeno estudado, o foco é o significado que as pessoas dão as coisas e a vida (Pereira et al., 2018).

O CTR é uma unidade de diálise privada, anexada ao Hospital São Luiz e oferece aos pacientes DRCTs, TRS na modalidade de hemodiálise, por meio de convênio com o Sistema Único de Saúde (SUS) e outros convênios (particular e planos de saúde), com atendimento aos pacientes de segunda-feira à sábado (CNES, 2020).

Além de consultas com médicos nefrologistas, clínico geral, conta com uma equipe multiprofissional, atendendo assim pacientes de Cáceres e região, sendo o principal setor de referência para o município e a região do sudoeste de Mato Grosso, envolvendo 22 municípios vizinhos (CNES, 2020; Hartwig, Junior, \& Ignotti, 2018).

A população constitui-se por idosos em hemodiálise no CTR da cidade de Cáceres. A amostra foi composta por 16 idosos. A escolha da amostra da pesquisa foi feita por conveniência, isto é, participaram da pesquisa somente os usuários que aceitaram colaborar com a realização deste estudo quando convidados (Contente et al., 2018).

Os critérios de inclusão foram: ter idade de 60 anos ou mais; diagnóstico de IRC; estar em tratamento de hemodiálise no CTR no mínimo há 03 meses; apresentar capacidade cognitiva para responder as perguntas norteadoras; aceitar em participar da pesquisa e assinar o Termo de Consentimento Livre e Esclarecido (TCLE).

Os critérios de exclusão foram: idosos em tratamento de hemodiálise que realiza tratamento contínuo em outra unidade de diálise (p. ex. viajantes), pacientes com deficiência auditiva e capacidade cognitiva prejudicada.

A coleta dos dados ocorreu entre os meses de julho à novembro de 2020, e deu-se por meio de entrevista gravada individualmente no momento que precede ou após o procedimento de hemodiálise. Os dados não foram coletados de prontuários médicos.

Para nortear a entrevista foi utilizado um questionário semiestruturado, composto de perguntas abertas, abordando: dados pessoais (idade, sexo); dados sociodemográficos (cor da pele, situação conjugal, município de residência, religião, renda familiar, ocupação, escolaridade, religião); dados clínicos (tempo de hemodiálise, tipo de acesso, doença de base, e comorbidade).

O questionário abordava também as questões norteadoras sobre a dificuldade do idoso em aceitar o diagnóstico da doença renal terminal, dificuldade do idoso em aceitar o tratamento de hemodiálise e sobre as dificuldades que o idoso encontrou após iniciar o tratamento de hemodiálise.

A entrevista foi gravada e transcrita na íntegra e armazenada em um banco de dados, construído no programa computacional Microsoft Wordl® Professional 2016. Posteriormente foi realizado uma pré análise de forma organizativa do material tornando as ideias operacionalizadas e sistemáticas em etapas, em seguida realizou-se a fase exploratória com a classificação, codificação e categorização dos dados, para realizar o tratamento dos resultados, inferências e interpretação (fase de informações destacadas para analisar "o recorte"). Os dados foram analisados por meio da análise temática de Bardin (Farago \& Fofonca, 2007).

Os resultados alcançados na pesquisa durante a entrevista foram agrupados em categorias que melhor retratarem os conteúdos das falas de cada idoso entrevistado. Desta forma as categorias emergidas após a análise dos dados foram acerca das 
principais dificuldades que os idosos vivenciaram durante a aceitação da doença renal e do tratamento de hemodiálise, sobre as dificuldades que eles vivenciaram após ter iniciado o tratamento dialítico e a importância do apoio da família e da equipe multiprofissional.

Conforme estabelecido na Resolução nº 510/16, sobre Pesquisa Envolvendo Seres Humanos, o presente estudo foi realizado somente após a aprovação do Comitê de Ética em Pesquisa (CEP), da Universidade do Estado de Mato Grosso, conforme parecer favorável de nº 3.904.106.

Para manter o anonimato os entrevistados foram identificados com letras (P) referente a paciente, e posteriormente codificados com numeração $(1,2,3 \ldots 16)$, conforme ocorreu a entrega do TCLE e as entrevistas. Os pacientes entrevistados foram orientados quanto aos riscos e benefícios da pesquisa e a entrevista ocorreu somente após aceitarem as condições éticas mediante assinatura do TCLE.

\section{Resultados e Discussão}

A caracterização do perfil dos idosos segundo dados pessoais, sociodemográficos e clínicos foram: dos 16 participantes, 50\% eram do sexo feminino e 50\% do sexo masculino, com idade média de 68 anos (60 e 81 anos). Com relação a raça $81 \%$ dos pacientes se auto declararam da cor branca e $19 \%$ da cor negra. Referente a situação conjugal $56 \%$ dos pacientes alegaram serem casados, sobre a religião $81 \%$ responderam serem católicos.

No tocante a escolaridade dos pacientes 19\% alegaram serem analfabetos e $37,5 \%$ dos pacientes concluíram o ensino fundamental, outros 37,5\% não concluíram o ensino fundamental e 6\% possuía nível superior. No quesito ocupação $44 \%$ dos pacientes ajudam nos serviços domésticos.

Referente ao município de residência 56\% residem em municípios vizinhos a cidade de realizam do tratamento. Com relação a renda familiar 50\% dos pacientes possuem uma remuneração mensal de dois salários mínimos (Tabela 1). 
Tabela 1. Distribuição dos pacientes idosos segundo variáveis sociodemográficas.

\begin{tabular}{|c|c|c|c|}
\hline \multicolumn{4}{|c|}{ Dados Sociodemográficos } \\
\hline \multicolumn{2}{|c|}{ Variáveis } & \multirow{2}{*}{$\begin{array}{l}\text { Frequência } \\
\text { Absoluta } \\
13\end{array}$} & \multirow{2}{*}{$\begin{array}{l}\text { Frequência } \\
\text { Relativa } \\
81 \%\end{array}$} \\
\hline & Branca & & \\
\hline Cor & Negra & 3 & $19 \%$ \\
\hline \multirow{4}{*}{ Situação conjugal } & Solteiro (a) & 3 & $19 \%$ \\
\hline & Casado(a) & 9 & $56 \%$ \\
\hline & Separado (a) & 2 & 12,5 \\
\hline & Viúvo (a) & 2 & 12,5 \\
\hline \multirow[b]{2}{*}{ Religião } & Católica & 13 & $81 \%$ \\
\hline & Evangélica & 3 & $19 \%$ \\
\hline \multirow{4}{*}{ Escolaridade } & Analfabeto (a) & 3 & $19 \%$ \\
\hline & Fundamental Incompleto & 6 & $37,5 \%$ \\
\hline & Fundamental & 6 & $37,5 \%$ \\
\hline & Superior & 1 & $6 \%$ \\
\hline \multirow{4}{*}{ Ocupação } & Ajuda nos serviços da casa & 7 & $44 \%$ \\
\hline & Do Lar & 4 & $25 \%$ \\
\hline & Outros & 2 & $12 \%$ \\
\hline & Nenhuma/ Não responderam & 3 & $19 \%$ \\
\hline \multirow{7}{*}{$\begin{array}{l}\text { Município } \\
\text { Residência }\end{array}$} & Cáceres & 7 & $44 \%$ \\
\hline & Mirassol & 3 & $20 \%$ \\
\hline & Araputanga & 2 & $12 \%$ \\
\hline & Pontes e Lacerda & 1 & $6 \%$ \\
\hline & S. J. dos Q. Marcos & 1 & $6 \%$ \\
\hline & Porto Esperidião & 1 & $6 \%$ \\
\hline & Lambari D'Oeste & 1 & $6 \%$ \\
\hline \multirow{4}{*}{ Renda Familiar } & 1 salário & 7 & $44 \%$ \\
\hline & 2 salários & 8 & $50 \%$ \\
\hline & 3 salários & 1 & $6 \%$ \\
\hline & TOTAL & 16 & $100 \%$ \\
\hline
\end{tabular}

Fonte: Autores.

Com base nos dados clínicos dos pacientes, o tempo de hemodiálise variou de menor de um ano a mais de 15 anos, com maior predomínio de 5 a 10 anos (37,5\%). Dos entrevistados 81,2\% possuem como tipo de acesso a FAV, 12,5\% dialisam através do cateter duplo lúmen e 6,2\% faz uso do permicath. As doenças de base da IRC foram HAS (37,5\%), DM (31,2\%), HAS associado a DM (12,5\%), Rim Policístico (6,2\%), Glomerulonefrite $(6,2 \%)$ e Uropatia $(6,2 \%)$. A HAS e DM e ambas combinadas formam cerca $(81,2 \%)$ das doenças de base. Com relação as comorbidades mais prevalentes nos pacientes, houve um predomínio da HAS 3(37,5\%), DM (25\%) e HAS associada a DM (18,7\%) (Tabela 2). 
Tabela 2. Distribuição dos pacientes idosos segundo variáveis das condições clínicas.

\begin{tabular}{llll}
\hline Dados Clínicos & & & \\
\hline Variáveis & & $\begin{array}{l}\text { Frequência } \\
\text { Absoluta }\end{array}$ & $\begin{array}{l}\text { Frequência } \\
\text { Relativa }\end{array}$ \\
\hline \multirow{3}{*}{ Tempo } & Menor de 1 ano & 4 & $25 \%$ \\
Hemodiálise & de ano a 5 anos & 3 & $18,7 \%$ \\
& 5anos à 10 anos & 6 & $37,5 \%$ \\
& 10 anos à 15 anos & 2 & $12,5 \%$ \\
& Mais de 15 anos & 1 & $6,2 \%$ \\
\hline \multirow{3}{*}{ Tipo de Acesso } & FAV & 13 & $81,2 \%$ \\
& Cateter Duplo Lúmen & 2 & $12,5 \%$ \\
& Permicath & 1 & $6,2 \%$ \\
\hline \multirow{5}{*}{ Doença de Base } & HAS & 6 & $37,5 \%$ \\
& DM & 5 & $31,2 \%$ \\
& HAS + DM & 2 & $12,5 \%$ \\
& Rim Policístico & 1 & $6,2 \%$ \\
& Glomerulonefrite & 1 & $6,2 \%$ \\
Comorbidades & Uropatia & 1 & $6,2 \%$ \\
& HAS + DM & 3 & $18,7 \%$ \\
& HAS & 6 & $37,5 \%$ \\
\hline TOTAL & DM & 4 & $25 \%$ \\
\hline
\end{tabular}

Fonte: Autores.

\section{Percepções e vivências acerca do impacto da doença e o processo de aceitação do tratamento de hemodiálise}

A IRC estágio 5 é a condição mais avançada da doença renal e traz ao paciente não apenas redução da TFG, assim como perda das funções regulatórias, excretoras e endócrinas que o rim normal realiza, e todas essas alterações provocam no paciente, sérios danos à sua saúde e vários sinais e sintomas como anemia, HAS, edema, fraqueza, sintomas digestivos entre outros (Costa, Coutinho \& Santana, 2014; Xavier et al., 2014). Verifica-se nos depoimentos:

Tive que fazer mesmo porque final do ano eu já estava muito inchada e não tinha condições. (P 10)

[...] eu fui operar de uma hérnia no regional, e lá o potássio tava alto, [...] daí mandaram eu de ambulância pro dotor [...], aí ele falou que meu rim tava ruim. (P 16)

Por se tratar de uma doença silenciosa muitas vezes o paciente nem imagina que os sintomas podem estar relacionados a IRC, pode-se perceber na fala do paciente P 07:

[...] ]eu não tratei, eu tava achano que era problema de gripe se entendi, aí eu fui ficano meio fraco e tal, engordano e o corpo ruim, coisa e tal, e fui temano, isso é uma gripe, vai passar, semana que vem passa, passo uma semana passou outra semana, aí depois eu ruinei [...]. (P 07)

Conforme a fala do P 07 , percebe-se que os sintomas da IRC podem serem confundidos com sintomas de outras doenças, no caso do paciente, em seu relato ele aborda, "fui ficano meio fraco, engordano, e o corpo ruim", estas complicações manifestadas, levou o idoso a investigar seu problema de saúde. 
Diante disso, Kusumota, Rodrigues e Marques (2004), relata em seu estudo que as manifestações clínicas da IRC em fase terminal são entre elas a fraqueza geral, edema devido a retenção de líquidos, fadiga, sintomas estes que quando não diagnosticado e realizado tratamento pode evoluir para sérias consequências.

Contudo, faz-se importante mencionar que os sintomas relatados neste estudo, corroboram com os estudos de Kusumota, Rodrigues e Marques (2004) realizado com idosos com IRC, onde os pacientes relataram sentir fraqueza, inchaço, mal estar, anemia, sendo alguns dos principais sintomas que caracterizam a IRC em fase terminal.

Ainda em relação a IRC, como uma doença silenciosa, o P 13, relata sua vivencia:

Quando eu descobri o problema no rim, eu já comecei a fazê a hemodiálise, mais aí eu só tinha 10\% só, não tinha jeito. (P 13)

Galvão, Silva e Santos (2019), relatam que muitos pacientes que iniciam o tratamento de hemodiálise são em caráter emergencial, conforme observa-se no relato acima pelo P 13. Referem ainda que alguns pacientes iniciam o tratamento sem um preparo anteriormente, pressupondo que a sua obediência ao modo de proceder ao tratamento da TRS pode por vezes parecer traumática e dolorosa.

Desse modo o paciente acaba muitas vezes se impactando quando tem o diagnóstico da perda da função renal, o que de certa forma leva a uma dificuldade na aceitação do diagnóstico, conforme evidenciado na fala do P 07:

Tive, tive dificuldade porque eи que sou o culpado, entendi, eи memo sou o culpado, eu pensei que era uma gripe, e fui levando, fui trabaiano, levano e tal, aí o trem fico sério memo de verdade aí eu tive que sair, entendeu. (P07)

Conforme Silva et al., (2011), quando se descobre a presença da IRC e a necessidade em realizar um tratamento dialítico, no início pode ser visto com uma dificuldade e isto pode causar sofrimento físico e psíquico aos pacientes, as mudanças e limitações impostas ao paciente podem impactar negativamente na sua qualidade de vida. Percebe-se que estes eventos ocasionam no paciente um alto grau de estresse, dificultando a adesão do mesmo ao tratamento de HD.

Pode-se observar, através da vivência do idoso P 03 quando questionado sobre a dificuldade de aceitar o diagnóstico da IRC:

Tive, muita memo pra mim era um fim de vida, eu era sadio demais, até os 72 anos, não tinha nada mió do que eu, eu era mió do que todo mundo de saúde, tinha força, tinha disposição pra tudo. (P03)

Muitas vezes o idoso ao ter o diagnóstico de uma IRC em fase terminal, passa por um grande martírio, pois a doença causa um impacto psicossocial e merece atenção enquanto fator estressor e o paciente necessita passar por um processo adaptativo a essa nova condição de vida (Pilger et al., 2010; Rudnicki, 2014).

Cada paciente tem uma maneira única de vivenciar e enfrentar a mesma situação no seu processo de adoecimento, e isto faz com que o paciente tenha mais facilidade ou dificuldade de aceitar a doença e ao tratamento e isto permite compreender que nem toda situação estressora vem acompanhada de sofrimento (Rudnicki, 2014; Uema \& Pupilim, 2015).

$\mathrm{Na}$ vivencia do $\mathrm{P}$ 06, percebe-se que aceitar o diagnóstico da doença e a nova realidade pode contribuir na adesão ao tratamento. 
Não, não tive, não tive, nenhum problema e tamém não tenho desanimo nenhum de nada, porque é o seguinte, apareceu não foi porque eu quis, não sei quem mandô, então tem que aceita né, se o tratamento é a hemodiálise, tem que fazê a hemodiálise [...]. (P06)

O tratamento de hemodiálise vem como uma alternativa de vida aos pacientes com doença renal crônica terminal (DRCT), uma doença que transforma totalmente o cotidiano do paciente renal repercutindo em todas as dimensões e faz-se necessário que ele enfrente a vida com outro olhar (Pilger et al, 2010; Rosa \& Loures, 2013).

No paciente idoso, que já passa pelo processo de envelhecimento, em decorrência das alterações funcionais, fica mais suscetível às DCNT e também a apresentarem comorbidades, contudo, quando submetido a sessões de hemodiálise apresenta um grande motivo de impacto em diversas perspectivas de sua vida (Pilger et el., 2010; Rosa \& Loures, 2013).

A maneira como o idoso enfrenta a doença e o tratamento está interligada com o impacto que ambos causam em suas vidas, ambos influenciam na qualidade de vida e muitos apresentam frustações, medos e ansiedade que interfere no bem-estar físico psíquico e social, pois a doença muitas vezes é entendida como uma ameaça a vida trazendo incertezas acerca futuro (Galvão, Silva \& Santos, 2019).

Neste estudo, buscou-se retratar a maneira como foi vivenciado o processo de aceitação do tratamento de hemodiálise na perspectiva do idoso que a vivenciou. Quando questionado sobre a dificuldade da aceitação do tratamento de hemodiálise surgiram as seguintes vivencias:

Tive muita, muita, muita memo, eu chorava dia e noite e falava que queria morre, que eu não queria hemodiálise, e aí foi até que aconteceu, tive que se sedada, pá pode faze hemodiálise, depois que eu cheguei aqui, sei lá parece que me deu umas doidera lá. (P05)

Foi arrasante, pra mim é duro (silêncio) contrariava demais isso aí, que quando se entra no carro com um objetivo seu, tudo bem, mais entra forçado, eu entro nessa van é forçado, até hoje, eu sei que, eu tem que vim, então eu vou, já vai ta cá fistula tem tudo, mais eu entro contrariado. Aceito não, aceito na marra (pausa) é a natureza... (P03)

Conforme os relatos dos pacientes pode-se perceber que a necessidade do tratamento de hemodiálise ocasiona no paciente mudanças não somente nos hábitos de vida, mas também na percepção do seu próprio corpo, gera conflitos emocionais, produzindo sofrimento físico e psíquico (Pilger et al 2010; Cargnin et al., 2018).

Verifica-se nos depoimentos:

As maiores dificuldade foi no começo do tratamento, foi no começo, chegava daqui em casa tomava um banho e vestia uma camisola e chorava, chorava, chorava, pior não podia fica, me entende, ai meu Deus[...]. (P 01)

Não aceito, não aceito, queria ser normal, porque eu só trabalhei na vida e agora a gente sofrê (choro) uma coisa dessa né. (P 16)

Em estudos realizados por Pilger et al. (2010), com idosos em tratamento de hemodiálise, observaram que o tratamento causou impacto negativo e positivo nos pacientes, a depender da visão de cada um, quando encarrado de forma negativa na vida dos idosos, manifesta presença de sofrimento continuo e aflição. 
Conforme Santos et al. (2018) o fato de ser portador de uma doença renal e fazer a hemodiálise, é a proximidade com a morte, visto que não dialisar pode significar morrer, também há a possibilidade de durante o tratamento, presenciar situações críticas de companheiros de hemodiálise, e até suas mortes.

O medo da morte é um elemento constante, causa ansiedade e incertezas acerca do futuro, na vivencia a seguir, identificou-se a presença desse aspecto:

Várias dificuldades a gente nem lembra mais, mas eu não aceitava de jeito nenhum, de maneira nenhuma pensava esse trem não vai dar certo, eu vou morre, só pensava nisso, tinha medo de morre aqui dentro. (P 15)

[...] na verdade quem tem uma saúde mais ou menos, ele guenta muito tempo, agora quando a pessoa já tem problema ele chega aqui daí a pouco já vai embora, se vê quantos e quantos morreu junto com nois né, muitos e muitos. (P 15)

A aceitação do tratamento pode ser encarrada inicialmente como uma dificuldade, onde estes passam por um processo de rejeição e/ou aceitação. Nos relatos a seguir, percebe-se que o idoso ao aceitar a hemodiálise, facilita a adesão ao tratamento:

Sempre me vi como uma pessoa saudável. Tive muita dificuldade, pensei até suicida, sério [....]. Aí depois eu fui ver que a hemodiálise não é um bicho de sete cabeças, basta você aceitar. (P04)

Eu acostumei, gostei, daí eu vinha cedo pra cá, sabe porque, tinha bastante amigo aqui, fui conhecendo os outro, conhecendo os outro, e fui se abrindo mais também né, e o que que eu sou, num sô nada, sô pobre, pra que fica desse jeito, preciso mudar, aí mudei. (P01)

[...] eu aceitei bem, tava muito ruim então com a hemodiálise eu me senti bem. Se eu tive dificuldade para aceitar o tratamento, até que não, porque eu sabia que se eu não aceitasse era pior pra mim, então eu aceitei até fácil. (P 10)

Em um estudo realizado por Galvão, Silva e Santos (2019), acerca das dificuldades de encontradas pelos pacientes ao iniciar o tratamento de hemodiálise $76 \%$ dos pacientes afirmaram ter dificuldades de adaptação desde o início do tratamento.

Nos relatos acima foi possível observar que a opinião dos pacientes não é muito discrepante, contudo, percebe-se que cada idoso vivenciou seu processo de aceitação do tratamento de hemodiálise de uma maneira única, embora em suas vivencias possa haver sentimentos negativos e/ou positivos, eles reconhecem que o tratamento os mantém vivos (Cargnin et al., 2018).

Enquanto uns não aceitam chegar nessa fase da vida e ter seu cotidiano controlado pelas sessões de hemodiálise e as restrições impostas pelo tratamento, por outro lado há idosos que se conforma com a situação visto que é uma imposição causada por um problema de saúde e que o tratamento vai melhorar sua qualidade de vida (Uema \& Pupulim, 2015; Galvão, Silva \& Santos, 2019).

\section{O idoso em tratamento de Hemodiálise: principais dificuldades vivenciadas}

O tratamento hemodialítico também provoca alterações nos de hábitos de vida diária dos pacientes e nesta categoria os idosos expressaram suas vivencias em relação ao transporte, as condições de trabalho, mudanças alimentares e hídricas, o 
tempo das sessões de HD, o que exige de o paciente experimentar novos hábitos e adaptar-se a um novo estilo de vida. (Cargnin et al., 2018)

Sabe-se que a hemodiálise é o método de TRS mais comumente utilizado pelos pacientes com IRC e o Brasil possivelmente seja o terceiro maior programa de TRS crônica do mundo. (Oliveira, Formiga, \& Alexandre, 2018). A hemodiálise é um processo intermitente, realizado em média 3 vezes por semana ou até mesmo diariamente e cada sessão possui em média 4 horas. (SBN, 2020)

Para isso o paciente necessita se deslocar-se para uma clínica de tratamento especializada ou hospital de referência, e isso pode por diversas vezes gerar incomodo ao paciente idoso, principalmente para aqueles moram em outras cidades e o acesso para diálise é dificultado. Verifica-se as dificuldades conforme os depoimentos:

Encontrei e tá difícil até hoje essa viagem nossa, três veis por semana, tá muito cansativa entendeu, isso porque eu não era costumada tá saindo, entendeu, aí agora tem que sai entendeu. (P 05)

É as vezes eu pagava pra alguém vim me traze né, aí depois nois compramo um carro, aí meu guri trás eu, toda vez [...], nunca falhei. Tive que compra um carro pra facilita a vinda a clínica, muito ruim depender do transporte de secretaria. (P 02)

Essa viagem tá bem puxado três vez na semana pra quem morra em Araputanga pra vim, tá bem puxado, bem cansativo, eu quando eu chego lá eu chego nas últimas. (P 08)

A dificuldade é que lá na minha cidade não faz hemodiálise, tem que sair né, eu acho mais cansativo isso aí né, difícil a questão da viagem, acho cansativo. (P 12)

Diante dessas vivencias compreende-se que a maioria dos pacientes que residem em outros municípios apontam o transporte até a clínica como uma das principais dificuldades encontradas, ter que sair da sua cidade três vezes por semana, alguns chegam a viajar mais de 200 quilômetros, torna-se uma viagem cansativa até mesmo pela idade e as condições de saúde.

Em contrapartida, pacientes que residem no mesmo município onde realizam a hemodiálise, possui o acesso a clínica mais facilitado e isto torna menos exaustivo o tratamento. Verifica-se no depoimento do P 16:

Não usei o transporte da secretaria, eu saio daqui pego o moto táxi e em 5 minuto tô lá. [...] então eu agradeço muito a Deus por tá morando aqui, eu já vi muita gente da minha idade e eu pergunto onde se mora, outro dia eu perguntei pra uma pessoa que era de Pontes e Lacerda, quase três hora de viagem, como é que esse povo guenta uma pessoa de idade. (P 16)

Em um estudo realizado em um município do Estado de Goiás por Everling et al. (2016), observaram que 30\% dos pacientes se deslocam da cidade onde residem para fazer hemodiálise, ressalta ainda que os idosos se ressentem por sofrerem limitações para viajar, enquanto neste estudo dos idosos entrevistados 56\% dos pacientes residem outros municípios necessitando viajar três vezes por semana para estar realizando o tratamento de HD. 
Outra dificuldade elencada pelos idosos durante a entrevista foi sobre as condições de trabalho, para muitos o fato de não mais poder trabalhar gera um conflito emocional, perda parcial do convívio social, pois o trabalho é destacado tanto pela satisfação de suas necessidades de sobrevi

vência, quanto por desenvolver atividades que proporcionavam prazer e satisfação (Silva et al., 2011; Cargnin et al., 2018).

Mais difícil foi quando eu vi os colega de trabalho e eu não podia ir, o mais difícil pra mim foi isso aí, para de trabaia, foi o mais difícil. (P 09)

Para de trabaia né, foi difícil de aceita (silêncio). (P 16)

De acordo com Silva et al. (2011), o trabalho é um fator determinante no equilíbrio psicológico e Cargnin et al., (2018) ressaltam que a restrição ao trabalho provoca a perda da autonomia do indivíduo.

Conforme aponta no estudo mesmo com a idade avançada muitos idosos ainda tem o trabalho como fator importante em suas vidas e a incapacidade física para desenvolver as atividades de vida diária referente ao trabalho ocasiona sentimentos que afeta negativamente no seu modo de existir na sociedade e família, alguns sentem se inúteis, desanimados e pode diminuir sua autoestima (Uema \& Pupulim, 2015; Cargnin et al., 2018).

Durante a pesquisa foi abordado a restrição alimentar e hídrica como um dos fatores que para muitos foi encarado como uma das principais dificuldades, frustração, porém, mudar os hábitos alimentares é de suma importância para que não ocorra futuras complicações relacionadas a retenção de metabólitos no organismo (Everling et al., 2016).

Dessa forma, quando questionado aos idosos sobre as dificuldades encontradas após iniciar o tratamento de HD, surgiram as seguintes percepções:

Muda a alimentação mudo, porque me deram o papel (orientação da nutricionista) as coisas que não podiam comer, ainda tenho esse papel lá ainda, com o que eu podia come e que eu não podia come [...], feijão só o caldo, não pode come, banana nanica tamém não pode [...]. (P 06)

A alimentação judio um pouco, refrigerante que eu tomava muito não pode, fruta essas coisas, fruta que a gente comia não pode mais, então carne, toda vida eu comi carne demais, depois não pude comer mais, um pedacinho por semana, então fico muito difícil aceitar isso aí né. (P16)

Os relatos acima afirmam a real necessidade na mudança alimentar, estes relatos corroboram com estudos realizados por Uema e Pupulim (2015), no qual pacientes relatam a dificuldade de cumprir a dieta, não podendo ingerir certos alimentos que eram de costume.

Faz-se importante mencionar que as restrições alimentares e hídricas auxiliam no tratamento de hemodiálise, contudo também são fontes de frustações, pois o paciente necessita de uma mudança drástica nos hábitos alimentares e hídricos e isto determina várias privações. (Uema \& Pupulim, 2015)

[...] ]eu sinto uma fraqueza né, eu tento seguir né a dieta, o dotor [...] falou que é uma banana, uma laranja, uma coisa assim né, comer mais pouquinho. (P 08) 
[...] a alimentação normal, sal é pouco, e lá em casa todo mundo come comida mais em sonsa memo, a mesma comida a família inteira, fruta come normal, menos carambola essa nunca comi. (P 09)

Se bebe muita água fica muito pesado, o cara que ta com problema no rim bebe pouco, mas eu ainda urino um pouco, mas eu tô bem graças a Deus [...]. (P 06)

Cada vez que eu venho o máximo que eu tiro é um quilo e duzentos, cuido direitinho, eu não como o que não pode. (P 04)

A água tem dia que eu tomo muita água, quando tá muito calor, tem dia que eu sinto uma sede. (P 08)

De acordo com os estudos de Cargnin et al. (2018), os pacientes renais em hemodiálise relataram em depoimento a dificuldade em seguir as mudanças nos hábitos alimentares e hídricos, onde essa mudança acarretou em angustia e sofrimento além de interferir na relação do dia a dia.

Diante da perspectiva dos pacientes entrevistados neste estudo, vale ressaltar, que na vivencia cotidiana destes idosos, eles convivem com uma mudança nos hábitos alimentares e hídricos formados ao longo da vida e uma nova realidade onde permeia a necessidade de aceitar as restrições impostas para auxiliar o tratamento (Pilger et al., 2010; Cargnin et al., 2018).

Contudo houve pacientes que apontou o tempo de duração das sessões de hemodiálise, como mais uma entre as dificuldades encontradas, no cotidiano do tratamento. Desse modo o P 08 relata:

[...] é muito cansativo o tempo que fica na máquina, tem dia que me dá dor de cabeça, mas eu vou levando assim mesmo né. (P 08)

O fato de a hemodiálise ser um tratamento realizado três vezes durante a semana, e cada sessão levar em média quatro horas, o paciente permanece bastante tempo sentado, e isto para alguns idosos é sinal de desconforto além de cansativo (Pilger et al., 2010; SBN 2020).

Percebe-se que o tratamento de hemodiálise para estes idosos caracterizam como uma limitação em sua qualidade de vida, uma vez que os mesmos necessitam sair do aconchego de seu lar três vezes na semana para a realização do tratamento e gastam tempo envolvidos com as sessões de hemodiálise (Silva et al., 2017).

Além disso há as restrições alimentares e hídricas que são fundamentais no tratamento, porém gera dificuldades de adaptação aos novos hábitos, entretanto o apoio dos familiares e da equipe multiprofissional contribui para que o paciente possa sentir-se motivado em continuar o tratamento e incentivado a adaptar as dificuldades encontradas no tratamento (Galvão, Silva \& Santos, 2019).

\section{Fé, família e equipe multiprofissional: enfrentamento da doença e apoio na adesão ao tratamento.}

Conforme pode-se observar nas categorias anteriores, o idoso em tratamento de hemodiálise se depara com situações que ultrapassa os sinais e sintomas da doença.

Dessa maneira cada um com suas particularidades, em seu modo único de enfrentamento tanto da doença quanto do tratamento e suas limitações, convivem com alguns sentimentos de sofrimento, devido a momentos difíceis vivenciados como, rejeição, culpa, medos e lutas diárias para aceitar sua condição de vida e saúde (Souza, Devezas \& Santos, 2018). 
Entretanto, muitos pacientes se apegam a fé em Deus, para enfrentar esses momentos e ter uma melhor adesão ao tratamento:

[...] melhorei, tava inchada, inchada mesmo, tava o corpo inteiro inchada, e aí, daí pra cá, todo dia eu pedi pra Deus que se ele assim fizesse eu aceitar (choro), eu nunca ia deixar de reza o terço aqui dentro, rezo todo dia, todo dia que eu venho, eu rezo. (P 04)

Mediante a fala da P 04, é possível perceber que a sua fé em Deus, colaborou fortemente na aceitação do seu tratamento, e mesmo após anos de hemodiálise mantêm-se, firme em seu propósito, onde sua fé auxilia no enfrentamento das suas dificuldades e adaptações. Evidencia-se na sua vivencia:

[...] e aí foi só maravilha, [...] menina falar pra você, aqui perante Deus que ta me ouvindo, eu não tô mentindo, assim, foi assim que o milagre aconteceu. Graças a Deus, e agora assim como você me vê, a coisa mais difícil é eu passo mal, chego bem vou embora bem. (P 04)

Nessa perspectiva, Nepomuceno et al., (2014) descreve que a fatores relacionado a religiosidade manifesta impactos positivos na vida do paciente, melhorando os aspectos biopsicossocial, espiritual e na saúde dos pacientes, e Souza, Devezas e Santos (2018) acrescenta que fortalece a resiliência do paciente com DRT, melhorando a qualidade de vida frente à doença e o tratamento.

Outro fator primordial, é a interação e o apoio dos familiares, onde possibilita que o paciente enfrente a doença e o tratamento com mais facilidade, fazendo com que haja um controle dos pensamentos e emoções, assim como sensação de bemestar, além de um impacto e estímulos positivos para enfrentamento da doença e do tratamento (Galvão, Silva, \& Santos, 2019; Souza et al., 2020).

Evidenciou-se nas vivencias dos idosos, o quanto a família é importante no processo de mudança de hábitos, visto que o idoso já chega nesta fase da vida com os costumes e hábitos formados ao longo da vida (Souza et al., 2020).

Vejamos nas seguintes vivências:

[...] desde que eи comecei, eu tenho o apoio da família toda, minhas irmã, os parente, meu ex-marido, tudo da força assim pra mim, me ajuda muito, minha filha é muito companheira, só ela que me trais, desde que eu comecei, é ela que me busca me trais, é ela. (P 13)

[...] ]sempre meu genro que me ajudava e meus filhos, eu tenho 6 filhos, todos me ajudava [...]. (P 04)

Mediante os relatos acima, observa-se que o apoio familiar é essencial na vida destes idosos, tanto nos cuidados, quanto apoio financeiro e emocional.

Através deste estudo, pode-se perceber também que o tratamento de HD e suas restrições, afeta não só o paciente, mas a família que convive e auxilia este idoso no cuidado e no tratamento, trazendo em algumas situações diversos sentimentos, como medo, insegurança, sofrimentos e ansiedades, conforme os relatos dos P 11 e P 04:

[...] e aí minhas filhas sofreno de mais, sofreu muito elas e eu, elas cuidava igual uma criança até eu comer, pá mode de não deixa, até eu comer, pá sai de perto de mim, quando não era um era outro [...]. (P 11) 
Meus filhos sempre ajudou, e tem um filho, que esse sim não queria aceitar chorou até, chorou, chorou, chorou até, foi até que eu falei assim, não meu filho eu vou ter que fazer porque se eu não fazer eu vou morre, eu já tô numa fase bem avançada. (P 04)

Cargnin et al. (2018) relata em seus estudo que o apoio da família, vizinhos e sociedade pode ajudar no enfrentamento da doença, assim como o apoio da equipe multiprofissional na adesão ao tratamento.

Desta forma, durante as entrevistas, alguns idosos enfatizou sobre a importância que os profissionais da saúde têm com estes pacientes, principalmente na assistência prestada. Vejamos as percepções destes idosos:

[...] primeiro é que as meninas é uma maravilha, tem algumas trocas que você demora se adaptar com elas, ninguém é igual a ninguém né, então eles são muito bom pra ajuda, pra atender a gente, você faz assim e eles já tá tudo ali, querendo saber o que a senhora tá precisando se não tá passando bem. (P 04)

Com atendimento não tem nada que reclamar não. (P 09)

[...] aqui eles tratam a gente muito bem né, ajuda a gente muito rápido recupera, por causa que eles têm muita paciência, eu pelo menos dei muita sorte, tive muita sorte, tudo que eu pedi foi na hora [...]. (P 11)

Percebe-se que a equipe multiprofissional, principalmente a equipe de enfermagem, que são os que passam a maior parte do tempo com o paciente, tem um papel essencial na adesão ao tratamento destes pacientes, realizando uma assistência segura e com qualidade, preservando a humanização destes pacientes. Importante destacar sobre a vivencia no ambiente, pois cria-se um vínculo entre paciente e profissional, onde estes compartilham suas vivencias acerca do tratamento de hemodiálise (Pilger et al., 2010; Everling et al., 2016; Cargnin et al., 2018).

Vale ressaltar que tanto a família quanto a equipe têm a função de acompanhar e orientar o idoso em HD, quanto aos cuidados, o conhecimento da doença e da hemodiálise para que o idoso entenda as complicações, auxiliá-los a desenvolver suas potencialidades, a fim de que não se sintam dependentes e tenham uma melhor adesão ao tratamento, visto que mesmo cada um com seu modo único de seguir seu caminho, ambos tenham uma perspectiva de vida com mais qualidade e uma sobrevida maior (Pilger et al., 2010; Souza et al., 2020).

\section{Considerações Finais}

Diante das entrevistas realizadas, a pesquisa qualitativa permitiu a estes idosos expressar suas percepções ao seu modo, falar de si e como foi o processo de aceitação da doença e do tratamento em si e as principais dificuldades por eles vivenciadas, uma vez que cada um vivenciou de uma maneira distinta.

Este estudo revelou que embora exista o tratamento que lhes mantêm vivos, quando o paciente se depara com a hemodiálise, há reações positivas e negativas, assim como sentimentos de medo, insegurança, frustações, sofrimentos, e até conformismo por saber que há um tratamento que permita viver, com restrições que contribui para uma vida com menos complicações, aceitar a doença e a hemodiálise faz com que a jornada da vida seja mais leve, e o tratamento menos penoso.

$\mathrm{Na}$ busca por um melhor entendimento sobre as principais dificuldades vivenciadas pelos idosos em tratamento de hemodiálise, o afastamento do trabalho foi um dos pontos citados. O transporte, ou seja, a locomoção até a clínica de hemodiálise, foi uma entre as principais dificuldades, observou-se também grandes dificuldades quanto as restrições 
alimentares e hídricas e faz-se necessário o apoio dos familiares e a equipe da diálise auxiliando o idoso aprender a conviver com estas mudanças e limitações.

Vale destacar que o apoio dos familiares e a equipe multiprofissional, tem se mostrado fundamental nesta fase de vida, uma vez que o cuidado, o apoio emocional e o acolhimento a estes idosos pode promover uma melhor aceitação ao longo do tratamento contribuindo na sua adesão.

Levando em consideração estes aspectos, este estudo permitiu reconhecer as dificuldades vivenciadas pelos idosos, tanto no processo de aceitação da doença e tratamento, as dificuldades encontradas após iniciarem o tratamento assim como as mudanças acarretadas no processo de viver em tratamento de hemodiálise e o que fora essencial para enfrentar está nova condição de vida.

Conclui-se que o paciente renal necessita de total apoio dos familiares, sociedade, assim como dos profissionais de saúde que fazem parte do seu ciclo de vida, principalmente a equipe de enfermagem que necessitam estar atentos as necessidades destes idosos, saber ouvi-los e compreendê-los em sua individualidade e magnitude, demonstrando maior afetividade, apoio, confiança para que o idoso se sinta seguro em relatar suas dificuldades, medos e anseios, para que assim os enfermeiros possam estar ajudando-lhes na resolução das dificuldades encontradas, estabelecendo intervenções de enfermagem e criando ações educativas para promover uma melhor qualidade de vida para que apesar das limitações estes idosos possam viver melhor.

\section{Referências}

Brasil. (2006). Ministério da Saúde. Secretaria de Atenção à Saúde. Departamento de Atenção Básica. Envelhecimento e saúde da pessoa idosa. Ministério da Saúde, Caderno de Atenção Básica no 19. 192 p.

Cargnin, M. C. S., Santos, K. S., Gentelina, C. O., Rotoli, A., Paula, S. F. \& Ventura, J. (2018). Pacientes em tratamento hemodialítico: percepção acerca das mudanças e limitações da doença e tratamento. Revista de Pesquisa: Cuidado é Fundamental Online, 10 (4): 926.

CNES. Cadastro Nacional de Estabelecimento de Saúde. (2020). Consulta estabelecimento. http://cnes.datasus.gov.br/pages/estabele cimentos/ficha/identificacao/5102502394936.

Contente, S. R., Cavalcante, L. I. C., Silva, S. S. \& Heumann, S. (2018). Rotina E Qualidade De Vida De Usuários Em Terapia Renal Substitutiva. SPAGESP - Sociedade de Psicoterapias Analíticas Grupais do Estado de São Paulo, 19 (2): 81-93.

Costa, F. G., Coutinho, M. da. P. de. L. \& Santana, I. O. de. (2014). Insuficiência renal crônica : representações sociais de pacientes com e sem depressão, Psico-USF, 19 (3): 387-398.

Everling, J., Gomes, J. S., Benetti, E. R. R., Kirchner, M., Barbosa, D. A. \& Stumm; E. M. F. (2016). Eventos associados à hemodiálise e percepções de incômodo com a doença renal. Avances en Enfermería, 34 (01): 48-57.

Farago, C. C. \& Fofonca, E. A. (2007). Análise de conteúdo na perspectiva de Bardin: Do Rigor Metodológico À Descoberta De Um Caminho De Significações. Linguagem, 18: 1-5.

Galvão, A. A. F., Silva, E. G. da. \& Santos, W. L. dos. (2019). As dificuldades encontradas pelos pacientes com insuficiência renal crônico ao iniciar o tratamento. Revista de Iniciação Científica e Extensão, 2 (4): 180-189.

Guyton, A. C. \& Hall, J. E. (2011). Tratado de Fisiologia Médica. (12a ed.), Elsevier, 289-433.

Hartwig, S. V., Junior, A. L. de. S. \& Ignotti, E. (2018). Medicamentos para hipertensão de pacientes em hemodiálise em Cáceres - Mato Grosso, Brasil. Mundo da Saúde, 42(1): 158-180.

IBGE. (2018) Instituto Brasileiro de Geografia e Estatística (IBGE). Agência IBG Notícias. Número de idosos cresce $18 \%$ em 5 anos e ultrapassa 30 milhões em 2017.

Kusumota, L., Rodrigues, R. A. P. \& Marques, S. (2004). Idosos com Insuficiência Renal Crônica: Alterações no Estado de Saúde. Rev Latino-Am Enfermagem, 12 (3): 525-532.

Lima, A. F. C. \& Gualda, D. M. R. (2001). História oral de vida: buscando o significado da hemodiálise para o paciente renal crônico. Revista Escola de Enfermagem da USP, 35 (3): 235-241.

Nepomuceno, F. C. L., Melo Junior, I. M. De., Silva, E. De A. \& Lucena, K. D. T. de. (2014). Religiosidade e qualidade de vida de pacientes com insuficiência renal crônica em hemodiálise. Saúde em debate, 38 (100): 119 -128.

Neves, D. M. De M., Sesso, R. DE C.C., Thomé, F. S., Lugon, J. R. \& Nascimento, M. M. (2018). Censo Brasileiro de Diálise: análise de dados da década 
Research, Society and Development, v. 10, n. 4, e23310414010, 2021

(CC BY 4.0) | ISSN 2525-3409 | DOI: http://dx.doi.org/10.33448/rsd-v10i4.14010

2009-2018. Jornal Brasileiro de Nefrologia, 42 (2): 191-200.

Oliveira, G. T. C. De., Andrade, E. I. G., Acurcio, F. De. A., Cherchiglia, M. L. \& Correia, M. I .T. D. (2012). Avaliação nutricional de pacientes submetidos à hemodiálise em centros de Belo Horizonte. Revista da Associação Médica Brasileira, 58 (2): 240-247.

Oliveira, H. M. de. Jr., Formiga, F. F. C. \& Alexandre, C. da S. (2014). Perfil clínico-epidemiológico dos pacientes em programa crônico de hemodiálise em João Pessoa - PB. Jornal Brasileiro de Nefrologia, 36(3): 367-374.

Orlandi, F. De. S., Pepino, B. G., Pavarini, S. C. I., Santos, D. A. Dos., \& Mendiondo, M. S. Z. de. (2012). Avaliação do nível de esperança de vida de idosos renais crônicos em hemodiálise. Revista da Escola de Enfermagem da USP, 46 (4): 900-905.

Pereira A. S. et al. (2018). Metodologia da pesquisa científica. UFSM. https://repositorio.ufsm. br/bitstream/handle/1/15824/Lic_Computacao_MetodologiaPesquisa-Cientifica.pdf?sequence $=1$

Pilger, C., Rampari, E. M., Waidman, M. A. P. \& Carreira, L. (2010) Hemodiálise: Seu significado e impacto para a vida do idoso. Escola Anna Nery, 14 (4): $677-683$.

Rosa, K. R. \& Loures, M. C. (2013). Qualidade de vida de idosos em hemodiálise: Enfermagem e o lúdico. Revista de Ciências Ambientais e Saúde Estudos, Vida e Saúde, 40(4): 419-446.

Rudnicki, T. (2014). Doença renal crônica: vivência do paciente em tratamento de hemodiálise. Contextos Clínicos, 07(01): 105-116.

Santos, V. F. C. Dos., Borges, Z. N., Lima, S. O. \& Reis, F. P. (2018). Percepções, significados e adaptações à hemodiálise como um espaço liminar: a perspectiva do paciente. Interface - Comunicação, Saúde, Educação, 22 (66): 853-863.

Santos, I. Dos., Rocha, R. De. P. F. \& Berardinelli, L. M. M. (2011). Necessidades de orientação de enfermagem para o autocuidado de clientes em terapia de hemodiálise. Revista Brasileira de Enfermagem, 64(2): 335-342.

SBN. Sociedade Brasileira De Nefrologia. (2018). Doenças Comuns/Tratamentos - Hemodiálise. 2018. https://sbn.org.br/publico/tratatamentos/hemodialise/. Sesso, R. C., Lopes, A. A., Thomé, F. S., Lugon, J. R. \& Martins, C. T. (2017). Inquérito Brasileiro de Diálise Crônica 2016. Jornal Brasileiro de Nefrologia, 39 (3): 261-266.

Silva, A. S. Da., Silveira, R. S. Da, Fernandes, G. F.M., Lunardi, V. L. \& Backes, V. M. S. (2011). Percepções e mudanças na qualidade de vida de pacientes submetidos à hemodiálise. Revista Brasileira de Enfermagem, 64(5): 839-844.

Silva, K. A. L. DA, Cargnin, M. C. Dos S., Ventura, J., Paula, S. F. DE \& Groos, J. V. (2017). Qualidade de vida de pacientes com insuficiência renal em tratamento hemodialítico. Revista de Enfermagem UFPE on Line, 11(11): 4663-4670.

Souza, D. F. A. De, Pereira, B. C., Dázio, E. M. R., Vilela, S. De C., Terra, F. De S. \& Resck, Z. M. R. (2020). Perspectivas de vida e de viver de pessoas em tratamento hemodialítico. Ciência, Cuidado e Saúde, 19: 1-8.

Stevens, A. \& Lowe, J. (2002). Patologia. (2a ed.), Manole. 349-382.

Uema, R. T. B. \& Pupulim, J. S. L. (2015). Percurso E Expectativa De Vida Do Indivíduo Em Tratamento Hemodialítico. Revista de Enfermagem UFPE On Line, 9(10): 1500-1508.

Xavier, B. L. S., Santos, I. Dos, Almeida, R. F., Clos, A. C. \& Santos, M. T. dos. (2014). Caracteristicas individuais e clínicas de clientes com doença renal crônica em terapia renal substitutiva. Revista Enfermagem, 22(3): 314-320. 